\title{
Study on the Cultivation of Creative Quality in College Physical Education
}

\author{
Yazhou Wang
}

Hubei University of Automotive Technology, Shiyan, Hubei, 442000

Keywords: physical education; creative quality; cultivation method

\begin{abstract}
The quality of innovation is a kind of ability that contemporary college students must possess, and physical education has a unique role in cultivating college students. This paper analyzes the meaning of cultivating innovative qualities and puts forward the tactics of cultivating innovative qualities in college sports teaching to provide some help for the reform of physical education in colleges and universities.
\end{abstract}

\section{Introduction}

In order to improve the quality of physical education in colleges and universities, the physical and mental qualities of college students can be fully developed. The colleges and universities have been reforming their own physical education. Both the teaching philosophy and the teaching style have become more vivid and novel, and they have become more innovative for college students. The optimization of overall quality has played a certain role. Due to the constraints of traditional concepts and teaching methods, physical education in various universities has not achieved ideal results. In order to solve the current situation in physical education in all schools, physical education teachers in all schools began to integrate the cultivation of innovative qualities into physical education reform. We hope to play a role in effectively improving the problems in physical education.

\section{Status Quo of College Physical Education}

Although the advancement of teaching reform has improved the status of physical education teaching in colleges and universities, in some colleges and universities, physical education teaching has still not received due attention, whether it is the teaching model of physical education curriculum or the teaching schedule of physical education curriculum. There is a certain degree of randomness. There is no systematic plan for it. The teaching methods and evaluation methods of the teachers are all relatively simple. Some teachers still follow the competitive teaching model to carry out the teaching of physical education courses, which is not conducive to modernized physical education teaching methods. The development of physical education curriculum can be imagined.

The teaching method of teachers is a commonplace problem. Because the students' interest in learning and the willingness to learn a large part are determined by the excitement of the class, the teaching method has always been one of the focuses of the teacher. However, due to the bias in the emphasis on physical education curriculum, some teachers did not put a lot of energy into optimizing their own teaching methods. Their teaching methods are relatively rigid and boring, and the teaching aids used are also relatively old. The direct obstacle to the development of innovative quality training methods has been formed [1]. Moreover, the test method is still dominated by traditional forms and content. Such test scores cannot fully mobilize students' enthusiasm for learning. The quality of innovation ability training naturally cannot be optimistic. In addition, the traditional teaching method is based on the indoctrination model. The teacher will teach the students what they want to teach one by one, and then allow the students to imitate. This teaching method will not only obscure the students' learning objectives, but also The exercise of thinking ability has caused a certain degree of restriction, and most of them are learning more mechanically.

In some colleges and universities, the content of physical education is still dominated by athletics teaching. It does not fully understand the training of students' physical and mental health and the 
cultivation of innovative thinking. It also considers that when students are learning, as long as they master the movement skills and precautions of sports, they will achieve The purpose of teaching. This kind of competitive awareness has caused some misguiding on physical education in colleges and universities, and it has formed a certain gap with the original intention and objectives of physical education in colleges and universities, which is not conducive to the cultivation of students' innovative consciousness, and has not played a role in the purpose of training comprehensive ability in colleges and universities. .

\section{The Role of Cultivating Innovative Quality in College Physical Education Reform}

In order to cultivate students' innovative qualities in sports teaching, we must first give sufficient attention to college sports courses. In the era of quality education, all colleges and universities should also give full play to their own educational advantages. Through physical education, students can effectively exercise their minds and bodies, and gradually infiltrate the contents of their innovative consciousness into physical education. . Therefore, on the one hand, the leaders of all colleges and universities must comprehensively understand the importance and necessity of physical education in colleges and universities by studying, and optimize the physical education teaching hours and teaching equipment according to the actual situation of the school; on the other hand, they must pass through the school. Posters and radio and other forms of subtle influence on students, so that they clearly recognize the benefits of sports learning, and have a clearer understanding of the objectives of sports learning, and consciously increase the degree of emphasis on physical education courses, to protect the quality of the quality of innovation Improve the status of physical education courses in colleges and universities.

As the main auxiliary tools for physical education courses, classroom teaching equipment is the basis for the development of physical education classroom teaching methods. The speed and quantity of teaching equipment will have a direct impact on the effectiveness of physical education classroom teaching activities. Therefore, all universities and colleges should regularly The teaching equipment was counted, and the missing and damaged equipment were dealt with in a timely manner to provide guarantee for the development of physical education. When colleges and universities appropriately increase the teaching hours of physical education curriculum, each physical education teacher should innovate according to the teaching content of the curriculum in class to make it more enriched and interesting. In the course of curriculum design, teachers must change the past curriculum content is not closely connected and the teaching form is single and other issues, the value of physical education to fully tap out. It is necessary to make appropriate changes to the teaching content of the course according to the actual weather and the overall state of the students [2]. The teaching content of the course should be dynamically processed, and the opportunities for interaction between the students and the teacher should be increased, so that the atmosphere of the physical classroom changes. It is easier and more harmonious to facilitate teachers' education of students' innovative awareness. For example, in the basketball teaching, you can use the "Dribble Relay" game to replace the traditional warm-up mode. Divide the students into two groups. Set the dribble range according to the students' overall physical fitness. The shortest pair of time is the winner. , and can ask the other team to do one thing collectively. Using this kind of competition so that each student can seriously put into the activities, this will be better than the warm-up effect of the traditional model, and can enable students to strengthen their own dribble ability in the game process, can be described as double benefit.

Teachers are the main executors of innovative quality education in physical education curriculum. Therefore, the level of teaching methods will affect the final curriculum teaching effect. Therefore, all colleges and universities have to carry out further systematic training for teachers based on the original foundation. The standards of physical education reform allow teachers to understand and master the latest physical education theory and teaching methods, and constantly optimize the teacher's physical education quality, ensure the effect of innovative awareness teaching, and lay a good foundation for the development of students' comprehensive ability. 


\section{Strategies for Training Innovative Qualities in College Physical Education}

Combining with the relevant policy guidelines of the national education department for quality education, quality education is the development trend of contemporary education, and it is also an inevitable requirement to meet the needs of the talents for the times. As an important part of quality education, innovative quality should be valued by educators. Especially in physical education teaching, it is necessary to be able to carry out all-round discussion and research, combine physical education with the cultivation of students' creative qualities, give full play to the characteristics and advantages of physical education classrooms, and provide students with innovative quality education in the process of physical education teaching. With cultivation. Colleges and universities should adhere to the concept of quality teaching, teachers should be able to actively guide students to enhance their awareness of innovation and ability, in the daily sports class to be able to take into account the physical exercise and the cultivation of innovative qualities. Teachers should be able to lead by example and cultivate students' ability to innovate in the classroom as well as in life as well as to practice innovative operational skills [3]. The arrangement of physical education curriculum in colleges and universities should be able to closely match the needs of actual and innovative quality training, cultivate students' creativity and development thinking, instill in students the spirit of active exploration and research and development, be good at finding problems, solving problems, and handling problems, thereby cultivating students' innovative qualities.

In the physical education process in colleges and universities, we must adhere to the people-oriented teaching philosophy, restore the students' master status, cultivate students' initiative and creativity, create a good physical education environment, and diversify students' thinking and innovation. As one of the basic courses in colleges and universities, sports needs to pay more attention and attention. Infiltrating innovative quality as an important teaching content into daily teaching, and in accordance with the characteristics of students, strictly observe the following points. The first is the inquiry principle. Sexual thinking is the foundation for the cultivation of innovative qualities. It is necessary to stimulate students' desire to go to class through contextual teaching and cultivate inquiring thinking. The second is the principle of dynamics. Based on the daily sports skills and knowledge teaching, students are trained to study the dynamics of the problems and deepen the thinking on the issues so as to cultivate students' innovative qualities and consciousness. In addition, it also includes the principle of rationality, rationalized curriculum and teaching to stimulate students' imagination and creativity, and to explain and analyze students' perplexities and ideas in a timely manner, and to cultivate students' innovative qualities through reasonable guidance [4]. Finally, we must pay attention to the principle of personalization, we must be able to highlight the individual characteristics of students, highlight the characteristics of individuality, and cultivate students' innovative qualities through differentiated and personalized management.

Divergent thinking plays an important role in cultivating the quality of innovation. Specifically, it means that through the information and information obtained, it can be understood and analyzed in all directions. It can be considered from multiple angles and creatively find solutions to problems. Especially in the physical education teaching in colleges and universities to overcome the limitations of traditional teaching ideas, advocating students to open up innovation, implementation of democratic teaching, avoid using backward duck-style teaching methods, give students enough room for self-play and innovation. According to the teaching method of innovative quality in current physical education teaching in colleges and universities, the main teaching methods include the following. The first is the problem teaching method, which stimulates students' ability to handle and analyze problems through questions in the classroom, and cultivates innovative qualities through self-thinking and inquiry. Secondly, there are discovery-based teaching methods. By arranging specific tasks, students are asked to discover and discover the nature of the things and the significance of the tasks. In addition to the case teaching method, through the teaching of reasoning in class, students can have practical experience, obtain deeper insights and opinions, observe more information, and thus better stimulate students' imagination. Creative quality. The cultivation of innovative qualities in physical education teaching in colleges and universities is closely related to the arrangement of physical education curriculum and the setting of teaching materials. Scientific 
and rational teaching content has a great effect and effect on improving students' awareness of innovation [5]. Therefore, we must be able to combine the status quo of current college sports classrooms, strengthen the construction of the ranks of teachers, improve the professional qualities and levels of teachers, and ensure that innovative quality education has a good foundation. We must also be able to actively change the content and methods of traditional teaching, turn attention on skills into quality education, and be good at using the content of physical education classes to improve students' quality education, especially the cultivation of innovative qualities.

\section{Conclusion}

With the continuous development of education, quality education has become one of the most important topics that people pay attention to. Physical education in colleges and universities is no exception. It is necessary to be able to actively meet the needs of the nation and society for qualified personnel, and to cultivate high-caliber, high-caliber personnel in all directions. . In college sports teaching, it is necessary to be able to focus on cultivating students' creative qualities and to cultivate innovative talents.

\section{References}

[1] Cheng Yu. On the role and value of innovation quality cultivation in college sports education reform[J]. Contemporary Sports Science and Technology, 2014(8): 111,113.

[2] Hu Ruizhe. Strategies for deepening quality education in the teaching reform of public physical education in colleges and universities[J]. Knowledge Economy, 2012(10):161.

[3] Mei Lina. Cultivating Students' Creative Quality and Constructing a New Model of Extracurricular Sports Education in Colleges and Universities [J]. Value Engineering, 2011(20):205.

[4] Chu Chuan, Guan Yi. The role of innovation quality cultivation in college sports education reform[J]. SCIENCE, PUBLICATION, 2009(7):115.

[5] Huang Zhaowei. Discussion on the Role of Innovative Quality Training in Physical Education Reform in Colleges and Universities[J]. Culture \& Sports Equipment \& Technology, 2016(4):70,72. 